\title{
Assessment of trace metal contamination in peri-urban soils in the region of Kenitra - Morocco
}

\author{
Yahya El Idrissi ${ }^{1}$, Bouamar Baghdad ${ }^{2}$, Hamid Saufi ${ }^{3}$, Mohammed, El Azzouzi ${ }^{1, *}$, Abdelfettah Benchrif ${ }^{4}$, \\ Soukaina El Hasini ${ }^{1}$, Abdelali El Mekkaoui ${ }^{5}$ and Elhabib El Azzouzi ${ }^{6}$ \\ ${ }^{1}$ Laboratory of Molecular Spectroscopy, Chemistry Department- Faculty of Sciences, Mohammad V University, \\ Avenue Ibn Battouta, PB 1014, Rabat, Morocco \\ 2 Department of Natural Resources and Environment, Hassan II Agronomy and Veterinary Institute, \\ Madinat Al Irfane, 10101 Rabat, PB 6305 Morocco \\ ${ }^{3}$ ENS- Mohammad V University, Avenue Ibn Battouta, PB 1014, Rabat, Morocco \\ ${ }^{4}$ National Centre of Energy, Science and Nuclear Techniques, 14000 Kénitra, PB 1382, Morocco \\ ${ }^{5}$ Research unit on Environment and Conservation of Natural Resources, INRA, BP 415, Rabat-Morocco \\ ${ }^{6}$ Head of Geo-biodiversity and Natural Patrimony laboratory GEOPAC research center, \\ Mohamed V University, Rabat, Morocco
}

\begin{abstract}
The spatial distribution of trace metals in peri-urban soils from Kenitra city (Morocco) was investigated. A total of 10 soil samples $(0-20 \mathrm{~cm}$ depth) were collected from the studied area. The physico-chemical properties including $\mathrm{pH}$, electrical conductivity and texture were determined. Contents of 6 trace metals $(\mathrm{Cd}, \mathrm{Cr}, \mathrm{Cu}, \mathrm{Ni}, \mathrm{Zn}$ and $\mathrm{Pb}$ ) were measured using Atomic Absorption Spectrometry method (AAS).

The results showed that soils of Kenitra city have a sandy texture with a predominance of alkaline $\mathrm{pH}$. The analyzed soil samples can be considered as no salt due to low electrical conductivity values. The trace metals contents revealed that soils are uncontaminated.
\end{abstract}

Keywords: Trace metals, Peri-urban soils, Contamination, Kenitra city.

\section{Introduction}

Soil is the support of many industrial, agricultural and urban activities. Trace metals are released into the soil by natural processes ${ }^{1-4}$ like weathering/erosion of parent rocks and ore deposits or by anthropogenic activities like industries, urban (heating, sewage, waste water sludge), transport (road, water) and agriculture (fertilizers, herbicides).

Pollution can be divided in two categories: i) the first one is point source pollution, generally reduced to the plot and most often caused by agricultural, industrial and urban activities, and ii) the second called nonpoint-source pollution, that occur on a regional scale, whose vector is the often atmospheric (smoke thermal, metallurgical plant ...).

The accumulation of trace metals in soil can have adverse impacts on the environment, mainly the risk of contamination of crops, surface and groundwater ${ }^{5-8}$. This work is conducted to assess heavy metal contamination in peri-urban soils from Kenitra city.

*Corresponding author: Mohammed El Azzouzi

Email address: elazzouzim@outlook.com

DOI: http://dx.doi.org/10.13171/mjc8219042505mea

\section{Material and methods}

\section{Study area}

Our studied region is located in the northwest of the country, given the proximity of the Atlantic Ocean; Kenitra city is influenced by a maritime subhumid climate.

Geologically Kenitra city is situated in the Gharb plain, so is composed by a substratum of Paleozoic age which incorporates sedimentary and metamorphic rocks : schist, quartzite and limestone overcame by red clay deposits of Trias and by dolomites and dolomitic limestones of Jurassic and Cretaceous periods. The Miocene which constitutes the impermeable flooring of Gharb's Deep groundwater is formed by blue marls. In the Pliocene, the sedimentation has double origins: the first transgressions on the current coastal zone gave birth to a coastal sedimentation represented by sandstone and limestone. This formation of the coastal zone can reach $200 \mathrm{~m}$ thick and constitutes the most important aquifer; simultaneously and further upstream towards the east, continental sediments accumulate

Published April 25, 2019 
alternatively between coarse and fine according to the rainfall and violence of erosion on the continent during the period of its creation.

The transgressions of Quaternary were represented by calcarenite of the coast and by a carbonate detrital sedimentation with clay intercalations. The surface area coverage of Gharb plain is characterized by an extension of clay and sandy soils favorable to a wide range of cereal crops.

We choosed our site selection according to the proximity of highways, the location relative to main sources of pollution and population density. Ten samples were extracted, the geographic location is shown in Figure 1.

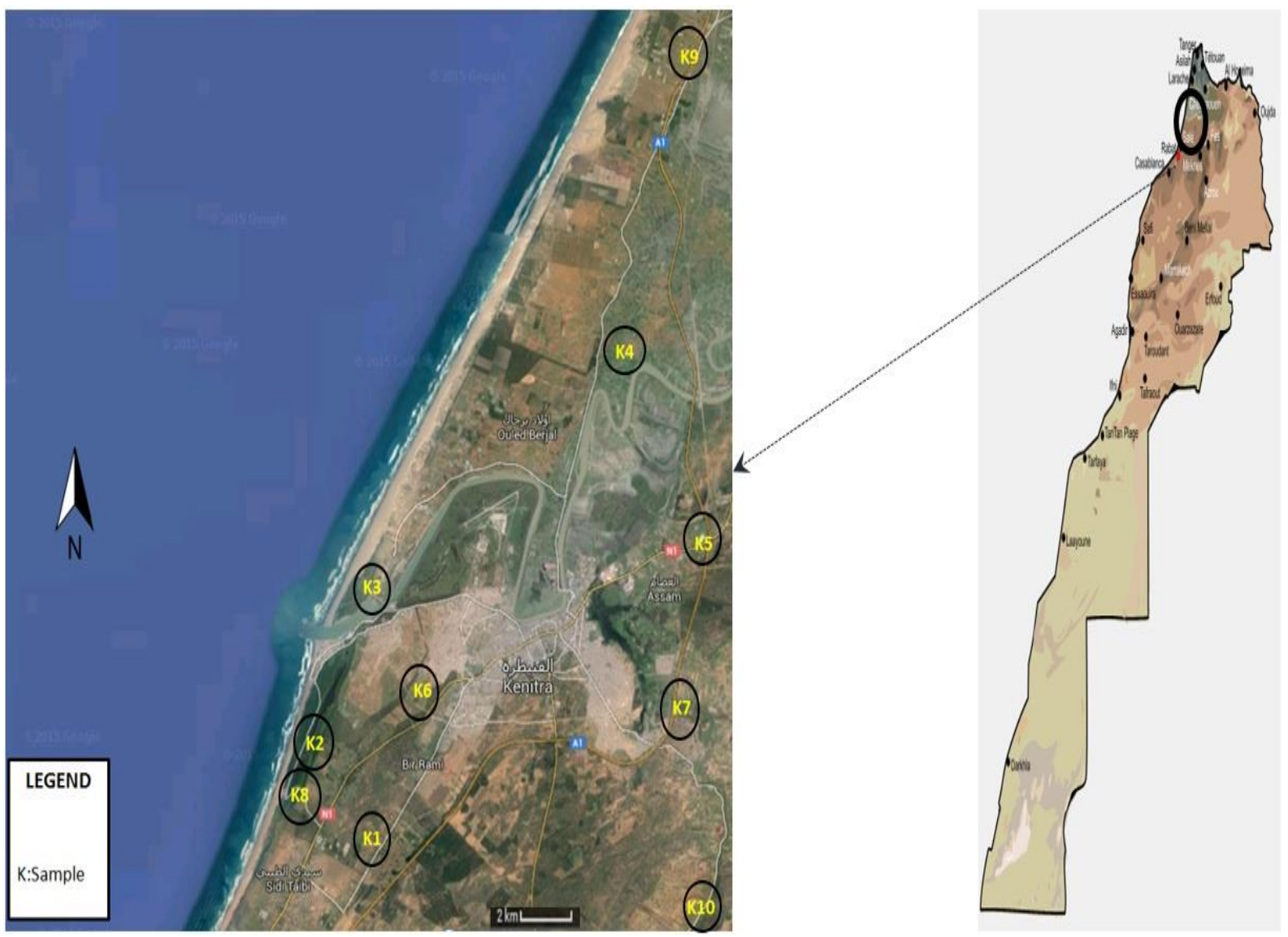

Figure 1. Location of the sampling points (Google Earth Picture)

\section{Physico- chemical analyses}

Surface soil samples were collected from a depth of 0-20 cm, and after air-drying; samples were passed through a $2 \mathrm{~mm}$ sieve. The analyses were performed on the fine fraction of soil whose diameter is less than $2 \mathrm{~mm}$.

The soil texture is a measure of the size of the elementary particles which constitute the soil, it was investigated by using granulometry analysis.

Soil pH was measured by in a slurry of soil. Weigh $20 \mathrm{~g}$ of soil. Add $50 \mathrm{ml}$ of distilled water, leave to rest for 30min without agitation, and pass the $\mathrm{PH}-$ meter in the sample.

The electrical conductivity was determined with glass electrode conductivity with a ratio of $1 / 5(10 \mathrm{~g}$ fine fraction to $50 \mathrm{ml}$ of distilled water). Sieve $10 \mathrm{~g}$ of soil, add $50 \mathrm{ml}$ of distilled water, leave to rest for 30 min. Shake and pass the sample under the measuring device, then read the result displayed on the screen.
A mineralization of the dry soil was performed by taking $0.5 \mathrm{~g}$ of the sample, put in the reactors, $1 \mathrm{ml}$ of $\mathrm{HCl}$ and $3 \mathrm{ml}$ of $\mathrm{HNO}_{3}$ are added. The solutions are allowed to stand until the end of the reaction. After that, we put them in the microwave for one hour.

So the determination of trace metals was made in an Atomic Absorption Spectrophotometer.

\section{Trace metals concentrations}

The Atomic Absorption Spectrometry was used to determine trace metals levels in sampled soils. This method, based on the theory of quantification of the energy of atoms, is used to determine chemical elements in trace state or in very small quantities (a few ppm) contained in a solution.

For the determination, we used the hollow cathode lamp that emits the specific spectrum of the element to be analyzed. The light beam passes through the receiving device. 
Analysis of Atomic Absorption Spectrometry uses the Beer-Lambert law equation:

\section{$\log I / I_{0}=$ K.L.C}

With:

* I and $\mathrm{I}_{0}$ : intensity of the incident beam and transmitted

* L: optical path length

* C: concentration of the element to be dosed

* $\mathrm{K}$ : coefficient that defines the ability of atoms to produce electrical transitions

\section{Contamination Index}

Some authors express metallic contamination with the contamination factor Fm (measured content / reference content with $\mathrm{Fm}>1$ ) and Im contamination index ${ }^{9-11}$.

$$
\mathbf{I m}=1 / \mathbf{n} \Sigma \mathbf{F m}
$$

With:

$\mathrm{n}$, the number of elements analyzed. These authors suggest that there is a beginning contamination for $\operatorname{Im}>2$.

\section{Results and Discussion}

\section{Granulometry analysis}

The granulometric analysis of our samples reflects an homogeneous distribution with a sandy texture. This texture distribution of all samples studied is shown in the following textural triangle.

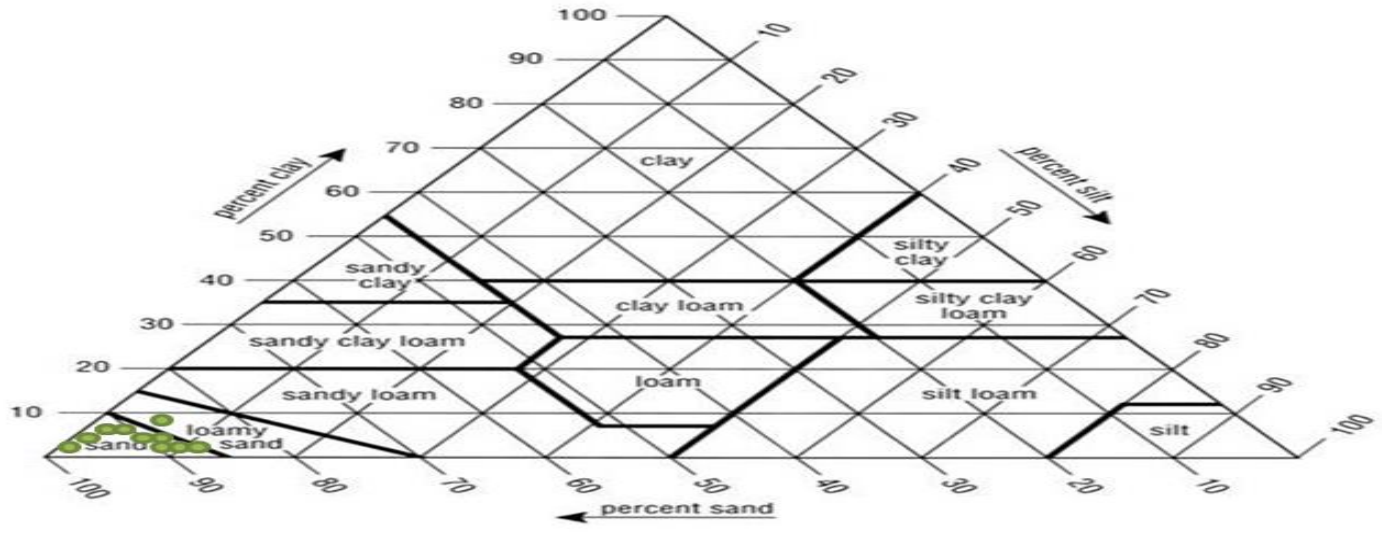

Figure 2. Distribution of samples in the textural triangle

\section{Soil pH}

The $\mathrm{pH}$ is a significant parameter, which controls chemical behavior of metals and other important processes in soil. As showed in Figure 3, the soil $\mathrm{pH}$ in Kenitra area is significantly different and it ranged between 6.68 and 8 . Most soils indicate values above 7 . The soil alkalinity can be attributed to the presence of carbonates in soil.

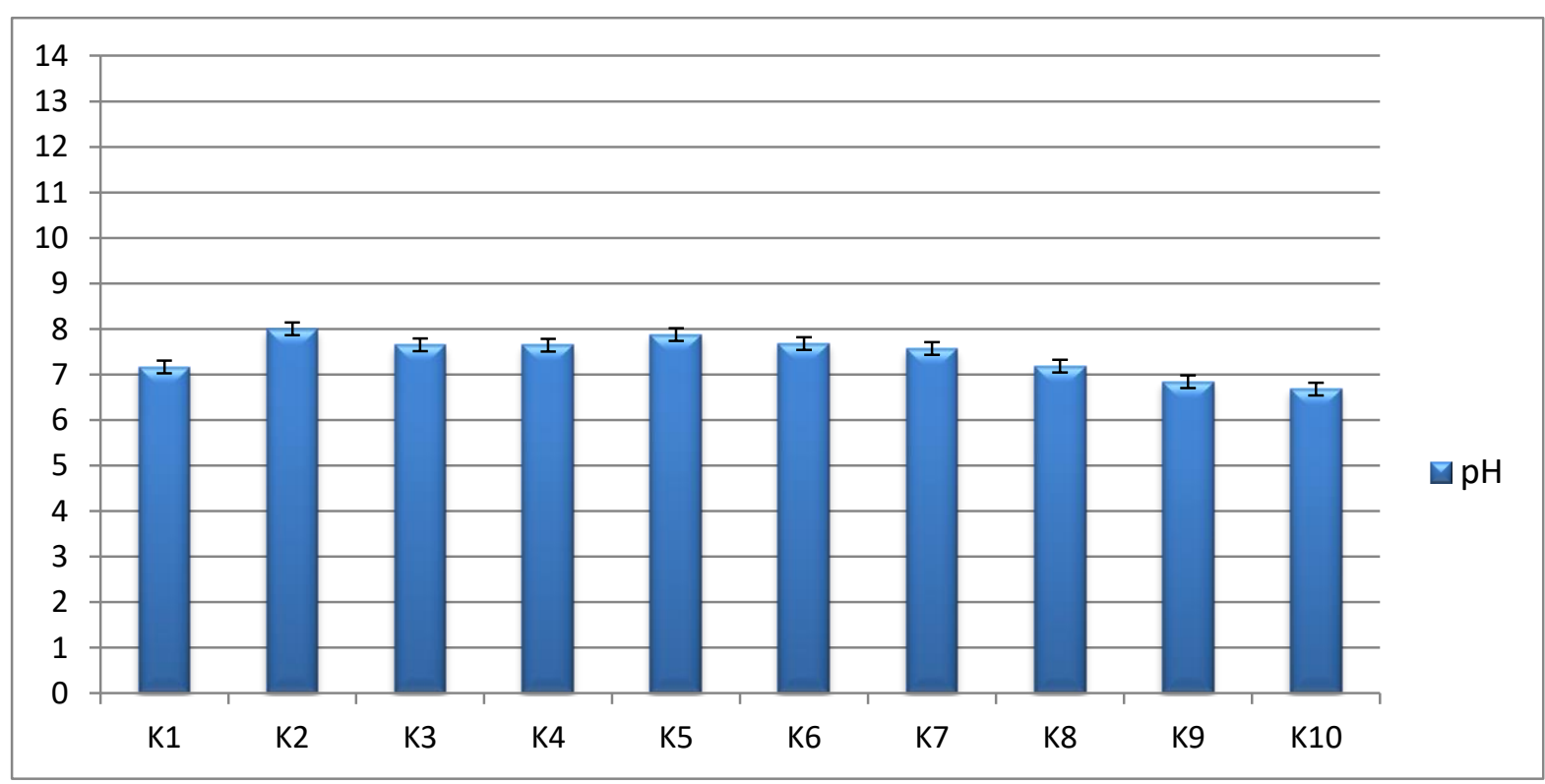

Figure 3. Soils $\mathrm{pH}$ in Kenitra area 
Electrical conductivity

According to results presented in Figure 4, soils of the studied area have low electrical conductivity, with a minimum value of $0.3 \mathrm{~ms} / \mathrm{cm}$ and a maximum value of $1.7 \mathrm{~ms} / \mathrm{cm}$. As a result, the investigated soils are classified as no salty.

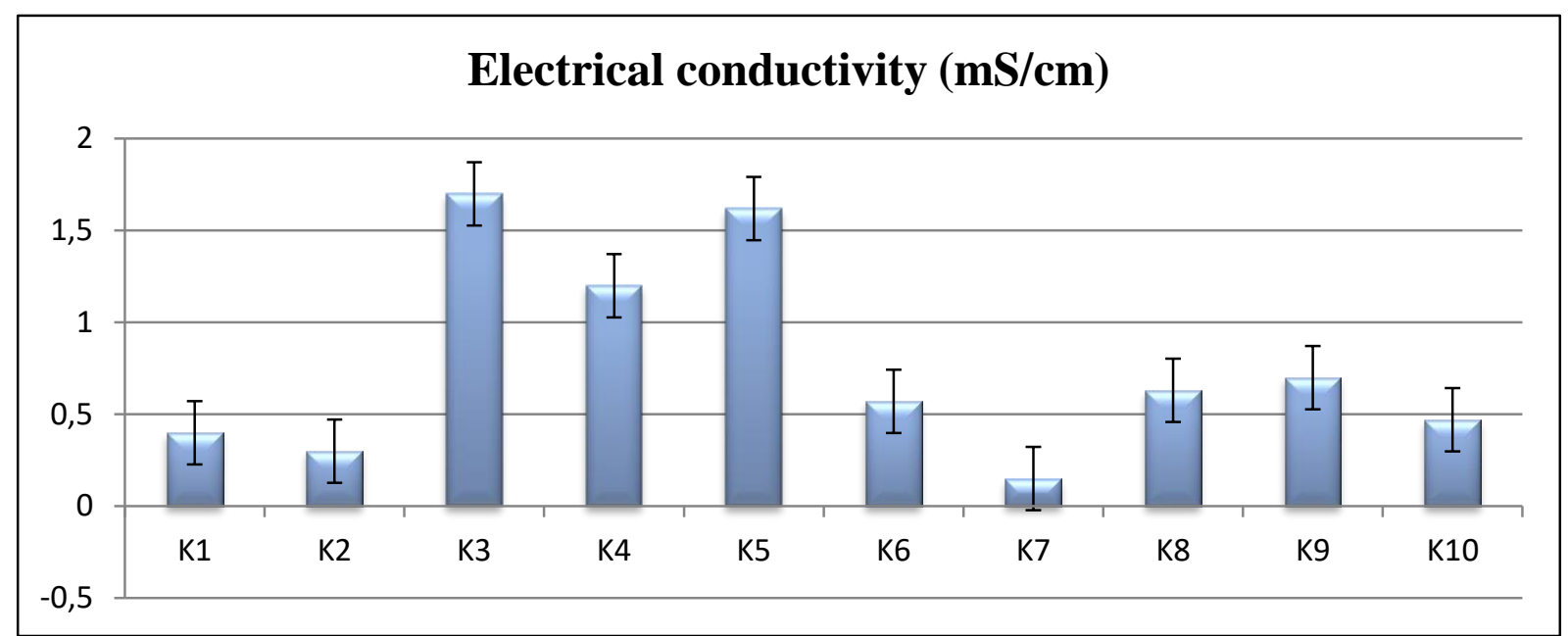

Figure 4. Electrical conductivity in soils of Kenitra area

\section{Concentrations of trace metals}

The minimum, average and maximum concentrations of trace elements analyzed $(\mathrm{Cd}, \mathrm{Cr}$, $\mathrm{Cu}, \mathrm{Ni}, \mathrm{Zn}$ and $\mathrm{Pb}$ ) in soils are summarized in Table 1.
The results showed that concentrations of trace metals are not high compared to normal levels of no contaminated soil ${ }^{12-15}$.

Table 1. Medium, minimum and maximum contents of heavy metals in soils in the region of Kenitra.

\begin{tabular}{|c|c|c|c|c|c|c|}
\hline & $\begin{array}{c}\mathrm{Cd} \\
(\mathrm{mg} / \mathrm{kg})\end{array}$ & $\begin{array}{c}\mathrm{Cr} \\
(\mathrm{mg} / \mathrm{kg})\end{array}$ & $\begin{array}{c}\mathrm{Cu} \\
(\mathrm{mg} / \mathrm{kg})\end{array}$ & $\begin{array}{c}\mathrm{Ni} \\
(\mathrm{mg} / \mathrm{kg})\end{array}$ & $\begin{array}{c}\mathrm{Zn} \\
(\mathrm{mg} / \mathrm{kg})\end{array}$ & $\begin{array}{c}\mathrm{Pb} \\
(\mathrm{mg} / \mathrm{kg})\end{array}$ \\
\hline Minimum & 0.02 & 0.02 & 1.07 & 5.05 & 0.02 & 0.02 \\
\hline Medium & 0.08 & 0.14 & 1.64 & 10.73 & 0.05 & 0.19 \\
\hline Maximum & 0.18 & 0.29 & 2.44 & 19.14 & 0.07 & $2-200$ \\
\hline$[1]$ & - & - & $5-80$ & - & $20-300$ & 35 \\
\hline$[2]$ & 0.35 & - & 30 & - & 90 & $10-30$ \\
\hline$[3]$ & $0.2-1$ & $70-100$ & $20-30$ & 50 & 50 & $9-50$ \\
\hline
\end{tabular}

[1] Fleming\&Parle (1977); [2] Normes (Bowen, 1979); [3] Alloway(1990; [4] Baize(1997)

The variation of heavy metal concentrations $(\mathrm{Cd}, \mathrm{Cr}$,
$\mathrm{Cu}, \mathrm{Ni}, \mathrm{Zn}$ and $\mathrm{Pb}$ ) between samples is shown in the Figure 5. 


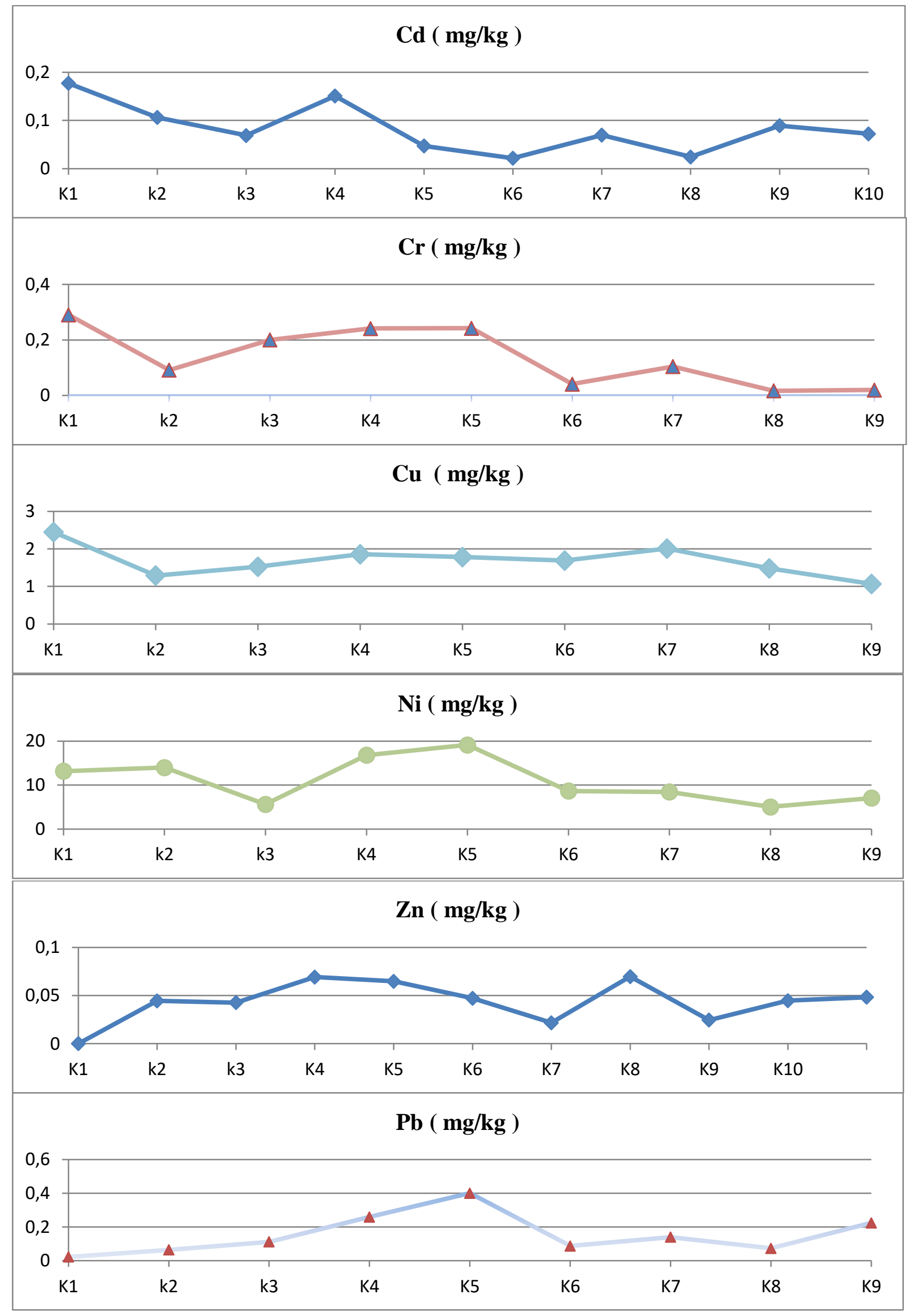

Figure 5. Contents of trace metals $(\mathrm{Cd}, \mathrm{Cr}, \mathrm{Cu}, \mathrm{Ni}, \mathrm{Zn}$ and $\mathrm{Pb})$ in the soils of Kenitra region 


\section{Calculation of Contamination Index}

The contamination index was calculated for studied trace metals using reference contents for uncontaminated soils. According to results presented in Table 2, it seems that the contamination index has values less than 2 for all studied elements. So, soils of Kenitra region can be classified as uncontaminated.

Table 2. Trace metals soil contamination indexes of Kenitra region.

\begin{tabular}{|c|c|c|c|c|c|c|}
\hline & $\operatorname{Im}(\mathrm{Cd})$ & $\operatorname{Im}(\mathrm{Cr})$ & $\operatorname{Im}(\mathrm{Cu})$ & $\operatorname{Im}(\mathrm{Ni})$ & $\operatorname{Im}(\mathrm{Zn})$ & $\operatorname{Im}(\mathrm{Pb})$ \\
\hline Fleming\& Parle (1977) & - & - & $\mathbf{0 , 2 7}$ & - & $\mathbf{0 , 0 4}$ & $\mathbf{0 , 4 1}$ \\
\hline Bowen (1979) & $\mathbf{0 , 3 9}$ & - & $\mathbf{0 , 0 9}$ & - & $\mathbf{0 , 0 8}$ & $\mathbf{0 , 0 2}$ \\
\hline Alloway (1990) & $\mathbf{0 , 6 9}$ & $\mathbf{0 , 0 0}$ & $\mathbf{0 , 1 4}$ & $\mathbf{0 , 3 6}$ & $\mathbf{0 , 0 8}$ & $\mathbf{0 , 0 8}$ \\
\hline Baize (1997) & $\mathbf{1 , 3 8}$ & $\mathbf{0 , 0 2}$ & $\mathbf{1 , 3 7}$ & $\mathbf{0 , 5 8}$ & $\mathbf{0 , 0 8}$ & $\mathbf{0 , 0 9}$ \\
\hline
\end{tabular}

\section{Conclusion}

The present study was conducted in Kenitra region in order to assess trace metals contamination in peri-urban soils. The studied area is characterized by a large population, an increasing industrial trend, large agricultural activities, and a considerable traffic rate.

The results of this study shows that the concentrations of trace elements $(\mathrm{Cd}, \mathrm{Cr}, \mathrm{Cu}, \mathrm{Ni}, \mathrm{Zn}$ and $\mathrm{Pb}$ ) in the studied area vary between the different elements, and from one site to another. However, we note the absence of contamination by the trace metals in the region.

Indeed, the levels of $\mathrm{Ni}$ and $\mathrm{Cu}$ in the sampled soils are important in the region. This enrichment can be attributed to urban activities and road traffic, in addition to industrial and agricultural activities.

The low enrichments of $\mathrm{Zn}$ can be explained either by the nature of the pedogeochemical ground of soil in the region and the adverse physico-chemical conditions to retention of this trace element.

Thus, the variation in concentrations of trace metals show that they are not governed only by anthropogenic inputs, but also by other parameters such as pedogeochemical ground, the physicochemical characteristics of soil and the phenomena of mobility.

\section{References}

1- J. Abraham, K. Dowling, S. Florentine, Assessment of potentially toxic metal contamination in the soil of a legacy mine site in Central Victoria, Australia Chemosphere, 2018, 192, pp. 122-132.

2- R. Gerdol, L. Bragazza, R. Marchesini, R. Alber, L. Bonetti, G. Lorenzoni, M. Achilli, A. Buffoni, N. de Marco, M. Franchi, S. Pison, S. Giaquinta, F. Palmieri, P. Spezzano. Monitoring of heavy metal deposition in Northern Italy by moss analysis. Environmental Pollution, 2000, 108, 201-208.
3- P. Rademacher, Atmospheric heavy metals and forest ecosystems. UN/ECE,Federal Research Centre for Forestry and Forest Products (BFH). Geneva; 2001, p. 75.

4- H. Uwizeyimana, M. Wang, W. Chen \& K. Khan, The eco-toxic effects of pesticide and trace metal mixtures towards earthworms in soil. Environmental Toxicology and Pharmacology, 2017, 55, 20-29.

5- D. Boust, J.M. Jouanneau, C. Latouche, Bull. (1981). Inst. Géol. Aquitaine Basin, 30 (1981) 72-78.

6- C. Tong-Bin, Z. Yuan-Ming, Z. MeiLei, H. Ze-Chun, W. Hong-Tao, C. Huang, F. KeKe, Y. Ke, W. Xiao, T. Qin-Zheng, Assessment of heavy metal pollution in surface soils of urban parks in Beijing, China. Chemosphere, 2005, 60, 542-551.

7- Y.Q. Wang, L.Y. Yang, L.H. Kong, E.F. Liu, L.F. Wang \& J.R. Zhu, Spatial distribution, ecological risk assessment and source identification for heavy metals in surface sediments from Dongping Lake, Shandong, East China. CATENA, 2015, 125, 200-205.

8- R. Bade, S. OH, W.S. Shin, Assessment of metal bioavailability in smelter-contaminated soil before and after lime amendment. Ecotox. Environ. Safe, 2012, 80, pp. 299-307.

9- H.J.M. Bowen, Environmental Chemistry of the Elements. Academic Press, New York, 1979.

10- C. Bi, Y. Zhou, Z. Chen, J. Jia, X. Bao. Heavy metals and lead isotopes in soils, road dust and leafy vegetables and health risks via vegetable consumption in the industrial areas of Shanghai, China. Sci. Total Environ., 2018, Volumes 619-620, pp. 1349-1357.

11- G. Fleming and P. Parle, Heavy metals in soils, herbage and vegetables from an industrialized area west of Dublin city. Irish Journal of Agricultural Research., 1977, 16:35-48.

12- D. Baize, Total contents of trace metals in soils (France). References and interpretation strategies, INRA Editions, Paris, 1997. 
13- U.A. Jayawardena, P. Angunawela, D.D. Wickramasinghe, W.D. Ratnasooriya \& P.V. Udagama, Heavy metal-induced toxicity in the Indian green frog: Biochemical and histopathological alterations. Environmental Toxicology and Chemistry, 2017, 36, 28552867.

14- S. Parra, M.A. Bravo, W. Quiroz, T. Moreno, A. Karanasiou, O. Font, V. Vidal, F. Cereceda.
Distribution of trace elements in particle size fractions for contaminated soils by a copper smelter from different zones of the Puchuncaví Valley (Chile). Chemosphere, 2014, 111, pp. 513-521.

15- B.J. Alloway, Soil processes and the behavior of metals. In Alloway, B.J. (ed.), Heavy metals in soils, 1990, 11-37. London. Blackie. 